${ }^{1}$ Hematology Department. Hospital del Salvador. Santiago, Chile.

${ }^{2}$ Radiotherapy Department, Fundación Arturo López Pérez. Santiago, Chile. ${ }^{3}$ Universidad Diego Portales. Santiago, Chile.

${ }^{4}$ Nephrology Department, Hospital del Salvador. Santiago, Chile.

The authors have no conflict of interests to declare. No founding was used in this article.

Recibido el 29 de abril de 2019, aceptado el 21 de agosto de

Correspondig autor: Camila Peña Avenida Salvador 364, Providencia, Santiago, Chile. camipena@gmail.com

\section{Prognostic impact of renal failure recovery in patients with newly diagnosed multiple myeloma}

\author{
CAMILA PEÑA ${ }^{1}$, XIMENA VALLADARES ${ }^{1}$, \\ CLAUDIA GAJARDO ${ }^{1}$, MOISÉS RUSSO ${ }^{2,3}$, ÁLVARO MORALES $^{4}$, \\ GONZALO CORREA ${ }^{4}$, RICARDO VALJALO ${ }^{4}$
}

\section{ABSTRACT}

Background: Renal failure $(R F)$ is a common complication in patients with newly diagnosed multiple myeloma (NDMM). Aim: To evaluate the frequency of RF in NDMM patients, and the prognostic impact of its reversibility. Material and Methods: A retrospective study evaluating demographic and clinical characteristics of 154 consecutive patients with NDMM was carried out. Estimated glomerular filtration rate (eGFR) was calculated at the beginning and at the end of the induction therapy. In addition, we evaluated renal responses (RR) according to the International Myeloma Working Group (IMWG) criteria. The induction regimen was based on thalidomide in all cases. Results: Fifty-three patients had $R F(34.4 \%)$. Complete renal response ( $R R$ ) was achieved in $51 \%$. Three years overall survival in patients without $R F$, with $R F$ and complete $R R$, and patients with $R F$ and any other $R R$, was 66, 47 and 13\%, respectively. Median survival was 53, 27 and 6 months, respectively $(p<0.01)$. In the multivariate analysis, $R F$ and hypercalcemia were independent predictors of a worse outcome. Conclusions: Achieving a complete RR in patients with NDMM, is associated with a better survival.

(Rev Med Chile 2019; 147: 1374-1381)

Key words: Bortezomib; Kidney; Multiple Myeloma; Renal Insufficiency.

\section{Impacto pronóstico de remisión renal en pacientes con mieloma múltiple de reciente diagnóstico}

Antecedentes: La falla renal (FR) es una complicación frecuente en pacientes con mieloma múltiple (MM). Objetivo: Evaluar la frecuencia de FR en pacientes con reciente diagnóstico de MM y determinar la importancia pronóstica de su reversibilidad. Material y Métodos: Se realizó un estudio retrospectivo de 154 pacientes consecutivos con MM. La función renal se evaluó mediante la tasa estimada de filtración glomerular al inicio y final de la terapia de inducción. Además, evaluamos las respuestas renales (RR) de acuerdo con los criterios del International Myeloma Working Group (IMWG). El régimen de inducción se basó en talidomida en todos los casos. Resultados: Cincuenta y tres pacientes presentaron FR (34,4\%) al diagnóstico. La RR completa se logró en $51 \%$. La sobrevida global (SG) a 3 años en pacientes sin FR, con FR y RR completa, $y$ 
pacientes con FR y cualquier otra $R R$, fue de 66, 47 y 13\%, respectivamente. La SG media fue de 53, 27 y 6 meses ( $p<0,01)$, respectivamente. En el análisis multivariado, la FR y la hipercalcemia fueron factores independientes de menor sobrevida. Conclusiones: Lograr una RR completa en pacientes con MM recién diagnosticado se asocia con una mejor sobrevida.

Palabras clave: Bortezomib; Insuficiencia renal; Mieloma múltiple; Riñón.

$\mathrm{R}$ enal failure (RF) is a well-known complication in patients with multiple myeloma (MM). RF occurs in $20 \%$ to $50 \%$ of patients at diagnosis ${ }^{1,2}$. Approximately, $10 \%$ will require renal replacement therapy (RRT) ${ }^{3}$. The RF in MM patients has historically been defined arbitrarily by the "CRAB" criteria (hypercalcemia, renal impairment, anemia and bone lesions) of the International Myeloma Working Group (IMWG), which was previously defined as $2 \mathrm{mg} /$ $\mathrm{dL}$ or greater creatinine levels. These criteria were updated in 2014, and the current definition includes creatinine clearance $<40 \mathrm{ml} / \mathrm{min}^{4}$. The criteria to define renal response (RR) are also specific for this disease ${ }^{5,6}$ and will be described later in this article. It is important to consider that RF determines worse short-term prognosis, decreasing survival of these patients. The introduction of the so-called "novel agents", such as bortezomib, thalidomide or lenalidomide, improved the survival of patients with MM and $\mathrm{RF}$, even reversing this condition ${ }^{8}$.

There are no studies that correlate the different degrees of reversibility of RF by IMWG criteria with the survival impact of patients in Chile or Latin America.

The aim was to evaluate the frequency of RF in $\mathrm{MM}$ at diagnosis, its reversibility with first-line treatment, and the impact of this response on survival.

\section{Material and Methods}

A retrospective, descriptive, single-center study was performed. Demographic and clinical characteristics of patients with MM consecutively diagnosed in our institution between 2013 and 2017 were evaluated. The frequency of RF and need for renal replacement therapy (RRT) were also evaluated. In addition, reversibility with first-line treatment defined by IMWG criteria was registered. The induction regimen was based on thalidomide in all cases. Renal failure was defined as a glomerular filtration rate estimated by MDRD of $<40 \mathrm{ml} / \mathrm{min}$, as recommended by the IMWG in 2014. This calculation incorporates creatinine, age, sex and ethnicity. Renal response (RR) was defined according to IMWG criteria. Complete RR (CR) was defined as the sustained improvement (at least two months) of creatinine clearance $(\mathrm{CrCl})$ or estimated glomerular filtration rate (eGFR) from baseline $<50 \mathrm{ml} / \mathrm{min}$ to greater than or equal to $60 \mathrm{ml} / \mathrm{min}$. Partial RR (PR) was defined as sustained $\mathrm{CrCl}$ improvement from baseline less than $15 \mathrm{ml} / \mathrm{min}$ at a value between $30-59 \mathrm{ml} /$ min. Minimal RR was defined as sustained $\mathrm{CrCl}$ improvement from baseline $<15 \mathrm{ml} / \mathrm{min}$ at a value between 15 and $29 \mathrm{ml} / \mathrm{min}$. Alternatively, if the basal level is 15 to $29 \mathrm{ml} / \mathrm{min}$, minimal RR was defined as an improvement at $30-59 \mathrm{ml} / \mathrm{min}$. No response (NR) was recorded if none of these criteria were met $^{6}$.

\section{Statistical analysis}

A descriptive statistical analysis was performed. Analytical statistics were performed with Student's $\mathrm{t}$ test, chi square or Fisher exact test as appropriate. Overall survival (OS) was calculated with Kaplan Meier curves, and comparisons were made using $\log$ rank tests. Uni- and multivariate analyses were calculated by the Cox regression test.

The corresponding Ethics Committee approved the present study.

\section{Results}

Of a total of 154 consecutive patients diagnosed with MM, 53 (34.4\%) fulfilled the RF definition, and $16(10.3 \%)$ required RRT.

The main characteristics of the cohort are presented in Table 1. Induction regimens were as follow: cyclophosphamide, dexamethasone and thalidomide (CTD) in 48\%. Melphalan, prednisone and thalidomide (MPT) was used as induction in 
Table 1. Main characteristics of the cohort

\begin{tabular}{|c|c|c|c|c|c|}
\hline & & $\begin{array}{c}\text { With RF } \\
\mathbf{N}^{\circ}(\%)\end{array}$ & $\begin{array}{c}\text { Without RF } \\
\mathbf{N}^{\circ}(\%)\end{array}$ & $\begin{array}{c}\text { All patients } \\
\mathbf{N}^{\circ}(\%)\end{array}$ & P-value \\
\hline Clinical features & $\begin{array}{l}\text { Total } \\
\text { Median age } \\
\text { Calcium }(\mathrm{mg} / \mathrm{dL}) \\
\mathrm{Hb}(\mathrm{g} / \mathrm{dL}) \\
\text { Male } \\
\text { LDH }\end{array}$ & $\begin{array}{c}53(34) \\
69 \pm 10 \\
11,5 \\
8,8 \\
21(40) \\
219\end{array}$ & $\begin{array}{c}101(66) \\
67 \pm 11 \\
10 \\
10,3 \\
43(43) \\
173\end{array}$ & $\begin{array}{c}154(100) \\
68 \\
10,6 \\
9,8 \\
65(42) \\
190\end{array}$ & $\begin{array}{c}0,18 \\
0,0008 \\
0,0002 \\
0,16 \\
0,01\end{array}$ \\
\hline Stage & $\begin{array}{l}\text { ISS I } \\
\text { ISS II } \\
\text { ISS III }\end{array}$ & $\begin{array}{c}0(0) \\
8(16) \\
41(84)\end{array}$ & $\begin{array}{l}25(27) \\
37(39) \\
32(34)\end{array}$ & $\begin{array}{l}25(17) \\
45(31) \\
73(52)\end{array}$ & $<0,0001$ \\
\hline Type of MM & $\begin{array}{l}\lg G \\
\lg A \\
\text { LC } \\
\text { Biclonal } \\
\text { Non secretory } \\
\text { IgM }\end{array}$ & $\begin{array}{c}17(34) \\
9(18) \\
22(44) \\
2(4) \\
0 \\
0\end{array}$ & $\begin{array}{c}60(62) \\
23(24) \\
10(11) \\
2(2) \\
1(0,5) \\
1(0,5)\end{array}$ & $\begin{array}{c}77(52) \\
32(22) \\
32(22) \\
4(3) \\
1(0,5) \\
1(0,5)\end{array}$ & $<0,0001$ \\
\hline
\end{tabular}

$\mathrm{Hb}$ : hemoglobin, LDH: lactate dehydrogenase , Ig: Immunoglobulin, LC: light chain.

$36 \%$. Thalidomide and dexamethasone (Taldex) in $15 \%$. Patients treated with cyclophosphamide, bortezomib and dexamethasone (CyBorD) as first line (only 3 patients) were excluded from this analysis. Dexamethasone doses was between 20 and $40 \mathrm{mg}$ in all cases. Only 16 patients (10\%) underwent autologous stem cell transplant (ASCT). No data from maintenance were obtained.

In the group of patients with $\mathrm{RF}$, the $\mathrm{M}: \mathrm{F}$ ratio was 1: 1.4. The median age was 69 years, ranging from 38 to 88 years. Among these patients, higher incidences of hypercalcemia $(p=0.0008)$, patients in ISS III stage $(\mathrm{p}<0.0001)$ and light chain MM $(\mathrm{p}<0.0001)$ were noted.

The median eGFR estimated by MDRD was $20 \mathrm{ml} / \mathrm{min}( \pm 4.47$ with $95 \% \mathrm{CI})$ at diagnosis and $58 \mathrm{ml} / \mathrm{min}( \pm 10.2$ with $95 \% \mathrm{CI})$ at the end of the induction (Figure 1).

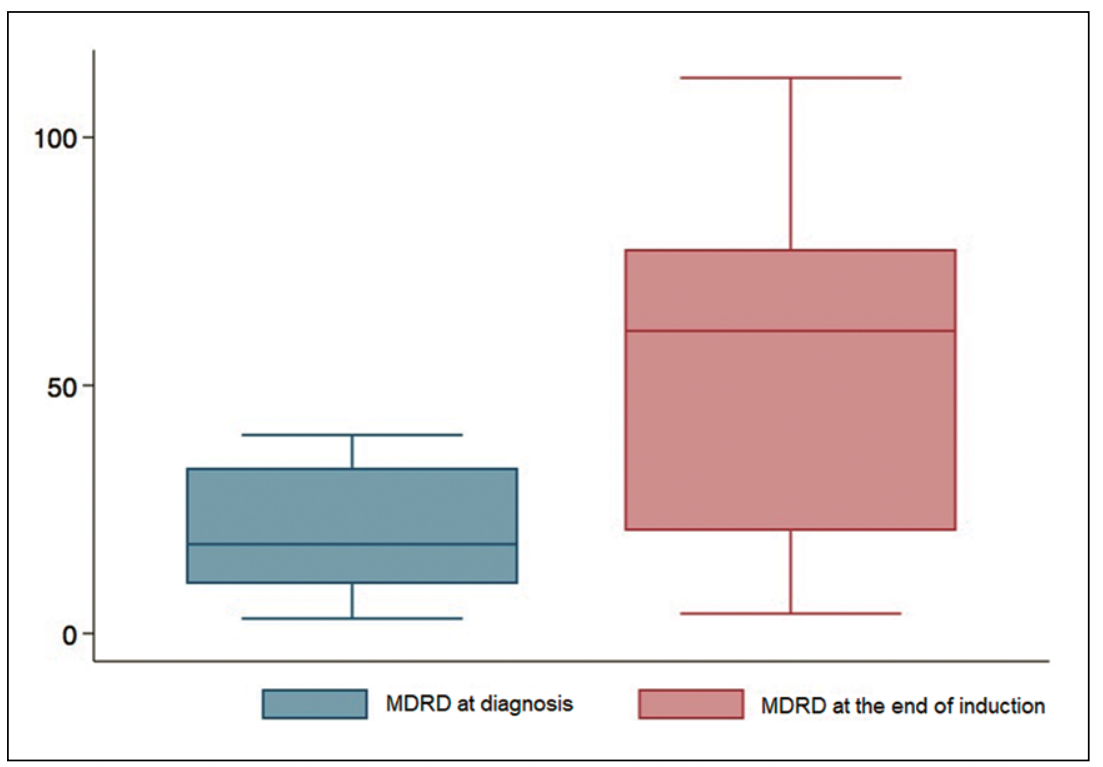

Figure 1. Estimated GFR by MDRD at diagnosis and at the end of treatment. 
The results regarding renal responses of patients in whom data were obtained (52 of the 53 patients) are shown in Table 2.

Three of the patients (19\%) became RRT independent.

The 3-year OS of patients without RF at diagnosis was $66 \%$ vs. $33 \%$ for those with $\mathrm{RF}$ ( $\mathrm{p}<0.0001$ ) with a median survival of 53 vs 15 months, respectively.

Among patients with RF with vs. without RRT, the median survival was 9 vs 22 months $(\mathrm{p}=0.05)$ with a 3 -year OS of $23 \%$ and $38 \%$, respectively (Figure 2).

When divided into 3 groups, including pa- tients without renal failure, patients with RF and complete $\mathrm{RR}$, and patients with $\mathrm{RF}$ and any other RR, the 3-year OS was 66, 47 and $13 \%$, respectively $(\mathrm{p}<0.001)$, and the median survival was 53, 27 and 6 months, respectively (Figure 3).

Univariate analysis by Cox regression showed that renal failure $(\mathrm{p}<0,001), \mathrm{LDH}$ above the normal range $(\mathrm{p}=0,075)$, ISS III stage $(\mathrm{p}=0,006)$, hypercalcemia $(\mathrm{p}<0,001)$ and age over 60 years $(\mathrm{p}=0,026)$ were related to a worse survival. Multivariate analysis showed that RF and hypercalcemia at diagnosis were independent prognostics factors (Table 3 ).
Table 2. Renal responses by the IMWG criteria

\begin{tabular}{|ccc|}
\hline Renal Responses (RR) & n (\%) \\
\hline Complete RR & 27 & $(51)$ \\
\hline Partial RR & 0 & \\
\hline Minor RR & 3 & $(6)$ \\
\hline No RR & 22 & $(43)$ \\
\hline No data & 1 & $(0)$ \\
\hline Total & $53(100)$ \\
\hline
\end{tabular}

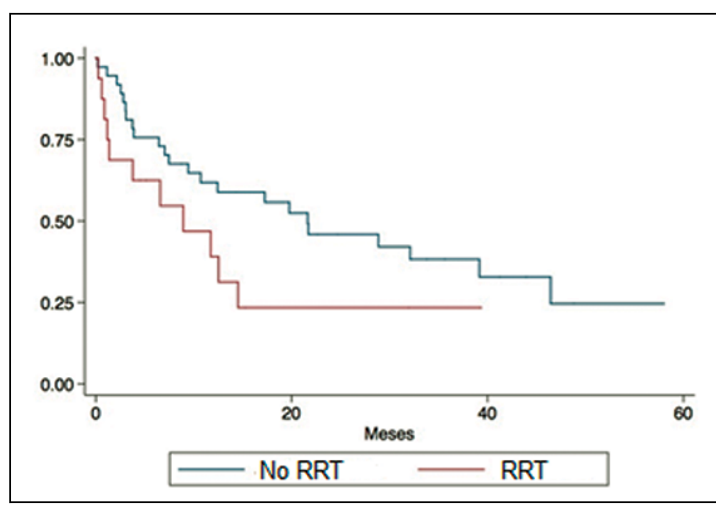

Figure 2. Kaplan Meier overall survival curves from patients with RF with or without renal replacement therapy.

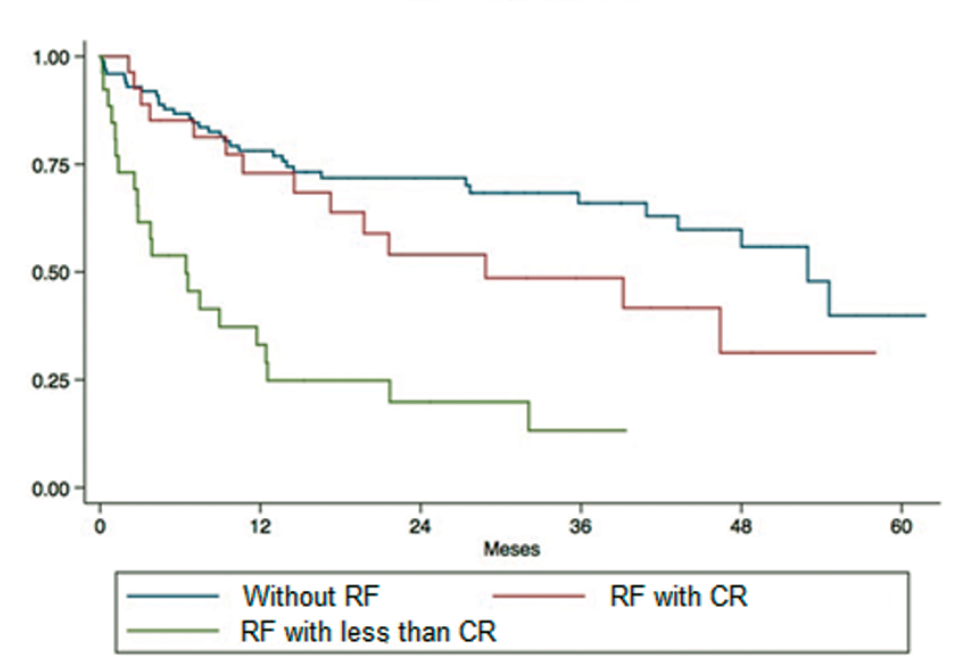

Figure 3. Kaplan Meier overall survival curves from patients divided into 3 groups, including patients without renal failure, patients with RF and complete RR, and patients with RF and any other RR. 
Table 3. Multivariate analysis of clinical and laboratory factors at diagnosis associated with Overall survival

\begin{tabular}{|lcccccc|}
\hline Variables & \multicolumn{2}{c}{ Univariate analysis } & \multicolumn{4}{c|}{ Multivariate analysis } \\
& HR (95\%Cl) & IC & p-value & HR (95\%Cl) & IC & p-value \\
\hline Renal failure & 2.15 & $1.61-2.87$ & $<0.001$ & 1.71 & $1.13-2.58$ & $\mathbf{0 . 0 1 1}$ \\
Elevated LDH & 1.76 & $0.94-3.29$ & 0.075 & 1.38 & $0.71-2.65$ & 0.338 \\
\hline ISS III & 2.04 & $1.23-3.41$ & 0.006 & 1.15 & $0.60-2.18$ & 0.677 \\
\hline Hypercalcemia & 2.9 & $1.77-4.74$ & $<0.001$ & 2.2 & $1.25-3.87$ & $\mathbf{0 . 0 0 6}$ \\
\hline Age $\geq 60$ & 2.09 & $1.09-4.00$ & 0.026 & 1.51 & $0.78-2.96$ & 0.223 \\
\hline
\end{tabular}

\section{Discussion}

We obtained a frequency of RF close to $40 \%$, which is higher to that described in the literature. As expected, our cohort of patients with RF was associated with adverse parameters, such as elevated LDH, hypercalcemia, anemia, advance ISS stage and light chain MM.

It must be highlighted that the incidence of RF depends on the definition used, which, as we have previously pointed, has changed over time. Using the old definition of creatinine $>2 \mathrm{mg} /$ dL, Dimopoulos et al. reported a RF frequency of $21 \%{ }^{9}$, and Kyle et al. reported a frequency of $19 \%{ }^{10}$. Knudsen et al. reported a $29 \%$ incidence using a definition of renal creatinine of $>1.3 \mathrm{mg} /$ $\mathrm{dL}^{11}$. Others have reported greater incidences, such as Park ${ }^{12}$, who described a $31 \%$ RF incidence based on a definition of $\mathrm{CrCl}<60 \mathrm{ml} / \mathrm{min}$. The equation used for RF is also variable. Similar to our group, currently, international studies use MDRD to measure RF. However, for acute RF, the RIFFLE or AKIN classification should be used instead. Very few studies in MM actually use these classifications ${ }^{13}$.

The frequency of patients who required RRT was also similar to the $10 \%$ classically described; as expected, this factor conferred a worse prognosis. The median survival of patients requiring RRT for life is less than 2 years ${ }^{14,15}$, and it was 9 months in our cohort. Only three (19\%) patients became independent of RRT. The RRT independence rate classically reported is $22 \%{ }^{16}$, which is similar to that achieved in our cohort. However, recent studies using novel agents, particularly bortezomib, reported a 44\% RRT independence rate from 2008 to $2014^{17}$. In 2017, Dimopoulos et al. reported $49 \%$ independence of RRT in their cohort of 52 patients ${ }^{18}$. The increase in RRT independence and survival in recent years is probably explained by the increased use of bortezomib, which was not available in our center at the time of the study.

Prior to the novel agents era, the survival of these patients with RF due to MM was very poor, ranging from 4 to 19.5 months of median survival (11), and the condition was mainly associated with early mortality (3). We reported a 15-month median survival, which is similar to that period. This could be explained by the fact that there was a suboptimal treatment in our cohort, with no patients receiving bortezomib ${ }^{19}$ nor high dose of dexamethasone ${ }^{20}$, some of them receiving doublets rather than triplets ${ }^{21}$, and with very few patients undergoing transplant ${ }^{22}$.

Thalidomide, an immunomodulatory drug (IMiD), is currently available in the Chilean public system. It does not require adjustment for renal failure and achieves RR rates between 55 and $75 \%$, which is similar to the $57 \%$ achieved in our cohort $^{23,24}$. Lenalidomide is also a current option, but it should be noted that it requires adjustment for renal failure. Therefore, lenalidomide is not the first choice in these cases ${ }^{25}$.

Proteasome inhibitors are the drugs of choice in RF in MM patients, especially bortezomib, which is the drug with the most robust evidence. It does not require dose adjustment and is usually administered with high doses of dexamethasone and thalidomide or cyclophosphamide. It can also be used in older patients in conjunction with melphalan; however, the latter requires dose adjustment. Bortezomib is associated with high rates of $\mathrm{RR}$ and longer 
survival ${ }^{16,19,26}$. Moreover, in a Swedish study, bortezomib was an independent favorable factor in the improvement of $\mathrm{RF}^{27}$.

Reversibility in RF improves survival in MM patients. Knudsen et al. reported 775 patients with $\mathrm{MM}$, in whom reversibility was noted in $50 \%$, representing an important prognostic factor for survival in this group ${ }^{11}$. Silva et al. ${ }^{28}$ reported a median OS of 40,2 months in patients who achieve major RR vs 24,8 months in no responders. Our study clearly revealed better survival in patients who achieved complete RR vs any other RR. Gonsalves et al. ${ }^{15}$ also reported this difference, with a reported median survival of 112 month in those patients without RF, 56 months in those with RF but who showed RR, and 33 months in those without RR. These data must encourage clinicians to apply the IMWG RR criteria in daily practice.

It seems that achieving RR is crucial, but the chosen drug for this purpose is also important. Dimopoulos et al. reported complete or partial RR of $77 \%$ with regimens based on bortezomib, $55 \%$ based on immunomodulators such as thalidomide and $43 \%$ with lenalidomide ${ }^{20}$. Similarly, Roussou et al. ${ }^{29}$ showed $79 \%$ improvement in RF with IMiDs vs $94 \%$ with bortezomib.

Half of our patients achieved complete RR, which seems relevant considering that no patient received the recommended drug bortezomib. However, based on all the current data, it becomes clear that bortezomib-based regimens are more effective, and, as we demonstrated in our study, higher levels of $\mathrm{RR}$ are associated with higher survival rates.

Acute RF is mainly produced by the formation and subsequent obstruction and inflammation of the distal tubules by light chain casts. This condition is attributed to a high tumor load ${ }^{30}$. A limitation of this study (besides its retrospective nature) is that very few patients underwent kidney biopsy. Acute RF was assumed in all these cases given the fact that there was no previous RF history. Indeed, some authors have shown that up to $15 \%$ of RF in MM is due to other causes, such as amyloidosis or monoclonal immunoglobulin deposit disease ${ }^{31}$. However, we can assume that the majority had a high tumor burden given that $98 \%$ presented with B2 microglobulin levels above the normal range, and these factors are correlated ${ }^{32}$. Also, the current recommendations of performing renal biopsy in MM patients are limited to patients with lower levels of paraprotein and no classical clinical course $e^{5,6}$.

\section{Conclusion}

Achieving complete RR according to the IMWG criteria in patients with newly diagnosed MM is positively related to increased survival. Therefore, prompt and effective treatment is crucial.

Although not common among the clinical practices in our country, we encourage use of the IMWG RR criteria given its usefulness in prognostically assessing these patients.

Larger and prospective studies are needed to corroborate our data.

\section{References}

1. Abbott KC, Agodoa LY. Multiple myeloma and light chain-associated nephropathy at end-stage renal disease in the United States: Patient characteristics and survival. Clin Nephrol 2001; 56 (3): 207-10.

2. Knudsen L, Hippe E, Hjorth M, Holmberg E, Westin J. Renal function in newly diagnosed multiple myelomaa demographic study of 1353 patients. Eur J Haematol 1994; 53 (4): 207-12.

3. Augustson BM, Begum G, Dunn JA, Barth NJ, Davies F, Morgan G, et al. Early mortality after diagnosis of multiple myeloma: analysis of patients entered onto the United Kingdom Medical Research Council trials between 1980 and 2002-Medical Research Council Adult Leukemia Working Party. J Clin Oncol 2005; 23: 9219 26.

4. Rajkumar SV, Dimopoulos MA, Palumbo A, Blade J, Merlini G, Mateos MV, et al. International Myeloma Working Group updated criteria for the diagnosis of multiple myeloma. Lancet Oncol 2014; 15: e538-48.

5. Dimopoulos MA, Terpos E, Chanan-Khan A, Leung N, Ludwig $\mathrm{H}$, Jagannath $\mathrm{S}$, et al. Renal Impairment in $\mathrm{Pa}$ tients With Multiple Myeloma: A Consensus Statement on Behalf of the International Myeloma Working Group J Clin Oncol 2010; 28 (33): 4976-84.

6. Dimopoulos MA, Sonneveld P, Leung N, Merlini G, Ludwig H, Kastritis E, et al. International Myeloma Working Group Recommendations for the Diagnosis and Management of Myeloma-Related Renal Impairment. J Clin Oncol 2016; 34 (13): 1544-57. 
7. Jung SH, Cho MS, Kim HK, Kim SJ, Kim K, Cheong JW, et al. Risk factors associated with early mortality in patients with multiple myeloma who were treated upfront with a novel agents containing regimen. BMC Cancer 2016; 16: 613.

8. Kumar SK, Rajkumar SV, Dispenzieri A, Lacy MQ, Hayman SR, Buadi FK, et al. Improved survival in multiple myeloma and the impact of novel therapies. Blood 2008; 111 (5): 2516-20.

9. Eleutherakis-Papaiakovou V, Bamias A, Gika D, Simeonidis A, Pouli A, Anagnostopoulos A, et al. Renal failure in multiple myeloma: incidence, correlations, and prognostic significance. Leuk Lymphoma 2007; 48 (2): 337-41.

10. Kyle RA, Gertz MA, Witzig TE, Lust JA, Lacy MQ, Dispenzieri A, et al. Review of 1027 patients with newly diagnosed multiple myeloma. Mayo Clin Proc 2003; 78: 21-33.

11. Knudsen LM, Hjorth M, Hippe E. Renal failure in multiple myeloma: reversibility and impact on the prognosis. Nordic Myeloma Study Group. Eur J Haematol 2000; 65 (3): 175-81.

12. Park S, Han B, Kim K, Kim SJ, Jang JH, Kim WS. Renal Insufficiency in newly-diagnosed multiple myeloma: analysis according to International Myeloma Working Group consensus statement. Anticancer Res 2014; 34 (8): 4299-306.

13. Shi H, Zhang W, Li X, Ren H, Pan X, Chen N. Application of RIFLE criteria in patients with multiple myeloma with acute kidney injury: 15-year retrospective, single center, cohort study. Leuk Lymphoma 2014; 55 (5): 1076-82.

14. Torra R, Blade' J, Cases A, López-Pedret J, Montserrat E, Rozman C, et al. Patients with multiple myeloma requiring long-term dialysis: Presenting features, response to therapy, and outcome in a series of 20 cases. Br J Haematol 1995; 91 (4): 854-9.

15. Gonsalves WI, Leung N, Rajkumar SV, Dispenzieri A, Lacy MQ, Hayman SR, et al. Improvement in renal function and its impact on survival in patients with newly diagnosed multiple myeloma. Blood Cancer J 2015; 5: e296.

16. Dimopoulos MA, Roussou M, Gavriatopoulou M, Zagouri F, Migkou M, Matsouka C, et al. Reversibility of renal impairment in patients with multiple myeloma treated with bortezomib-based regimens: identification of predictive factors. Clin Lymphoma Myeloma 2009; 9 (4): 302-6.

17. Laforet M, Jourde-Chiche N, Haddad F, Sallee M, Stoppa AM, Brunet PM, et al. Evolution in the treatment of multiple myeloma and impact on dialysis independence: data from a French cohort from 1999 to 2014. Blood Cancer J 2016; 6 (3): e409.

18. Dimopoulos MA, Roussou M, Gavriatopoulou M, Fotiou D, Ziogas DC, Migkou M, et al. Outcomes of newly diagnosed myeloma patients requiring dialysis: renal recovery, importance of rapid response and survival benefit. Blood Cancer J 2017; 7 (6): e571.

19. Dimopoulos MA, Richardson PG, Schlag R, Khuageva NK, Shpilberg O, Kastritis E, et al. VMP (bortezomib, melphalan, and prednisone) is active and well tolerated in newly diagnosed patients with multiple myeloma with moderately impaired renal function, and results in reversal of renal impairment: Cohort analysis of the phase III VISTA study. J Clin Oncol 2009; 27 (36): 6086-93.

20. Dimopoulos MA, Roussou M, Gkotzamanidou M, Nikitas N, Psimenou E, Mparmparoussi D, et al. The role of novel agents on the reversibility of renal impairment in newly diagnosed symptomatic patients with multiple myeloma. Leukemia 2013; 27 (2): 423-9.

21. Rajkumar SV. Doublets, triplets, or quadruplets of novel agents in newly diagnosed myeloma? Hematology Am Soc Hematol Educ Program 2012; 2012: 354-61.

22. Peña C, Rojas C, Rojas H, Soto P, Cardemil D, Aranda $S$, et al. [Survival of 1,103 Chilean patients with multiple myeloma receiving different therapeutic protocols from 2000 to 2016]. Rev Med Chile 2018; 146 (7): 869-75.

23. Fakhouri F, Guerraoui H, Presne C, Peltier J, Delarue $\mathrm{R}$, Muret $\mathrm{P}$, et al. Thalidomide in patients with multiple myeloma and renal failure. Br J Haematol 2004; 125 : 96-7.

24. Tosi P, Zamagni E, Cellini C, Cangini D, Tacchetti P, Tura S, et al. Thalidomide alone or in combination with dexamethasone in patients with advanced, relapsed or refractory multiple myeloma and renal failure. Eur J Haematol 2004; 73 (2): 98-103.

25. Dimopoulos M, Alegre A, Stadtmauer EA, Goldschmidt $\mathrm{H}$, Zonder JA, de Castro CM, et al. The efficacy and safety of lenalidomide plus dexamethasone in relapsed and/or refractory multiple myeloma patients with impaired renal function. Cancer 2010; 116 (16): 3807-14.

26. Morabito F, Gentile M, Ciolli S, Petrucci MT, Galimberti S, Mele G, et al. Safety and efficacy of bortezomib-based regimens for multiple myeloma patients with renal impairment: A retrospective study of Italian Myeloma Network GIMEMA. Eur J Haematol 2010; 84 (3): 223-8.

27. Uttervall K, Duru AD, Lund J, Liwing J, Gahrton G, Holmberg E, et al. The use of novel drugs can effectively improve response, delay relapse and enhance overall survival in multiple myeloma patients with renal impairment. PLoS One 2014; 9 (7): e101819. 
28. Park S, Han B, Kim K, Kim SJ, Jang JH, Kim WS, et al. Renal Insufficiency in newly-diagnosed multiple myeloma: analysis according to International Myeloma Working Group consensus statement. Anticancer Res 2014; 34 (8): 4299-306.

29. Roussou M, Kastritis E, Christoulas D, Migkou M, Gavriatopoulou M, Grapsa I, et al. Reversibility of renal failure in newly diagnosed patients with multiple myeloma and the role of novel agents. Leuk Res 2010; 34 (10): 1395-7.

30. Sathick IJ, Drosou ME, Leung N. Myeloma light chain cast nephropathy, a review. J Nephrol. 2019; 32(2): 18998.

31. Nasr SH, Valeri AM, Sethi S, Fidler ME, Cornell LD, Gertz MA, et al. Clinicopathologic correlations in multiple myeloma: A case series of 190 patients with kidney biopsies. Am J Kidney Dis 2012; 59 (6): 786-94.

32. Palumbo A, Avet-Loiseau H, Oliva S, Lokhorst HM, Goldschmidt H, Rosinol L, et al. Revised international staging system for multiple myeloma: A report from International Myeloma Working Group. J Clin Oncol 2015; 33 (26): 2863-9. 